\title{
Opioid Addiction in Rural North Carolina: A Criminal Justice and Public Health Issue
}

\author{
James F. Anderson ${ }^{1}$, Kelley Reinsmith-Jones ${ }^{2}$ \\ ${ }^{1}$ College of Arts \& Sciences, Professor of Criminal Justice, East Carolina University, Greenville, NC, USA \\ ${ }^{2}$ School of Health and Human Performance, Associate Professor of Social Work, East Carolina University, Greenville, \\ NC, USA \\ Correspondence: James F. Anderson, Professor, Department of Criminal Justice, East Carolina Uni versity, Greenville, \\ NC, USA.
}

Received: April 10, 2017

doi:10.11114/ijsss.v5i7.2495
Accepted: June 6, $2017 \quad$ Available online: June 19, 2017

URL: https://doi.org/10.11114/ijsss.v5i7.2495

\begin{abstract}
Opioid addiction and abuse has become a nationwide epidemic in America. Chief among the states where this behavior is most pervasive is North Carolina. Current statistics reveal that not only are addiction, abuse, and untimely deaths owing to overdose (especially from heroin use) are found in urban areas, but these behaviors are also pervasive in rural areas of the state where health experts and criminal justice officials struggle with the challenges of addressing public health and criminal justice consequences that come with drug addiction and abuse such as treatment, prevention, and punishments, respectively. Unlike urban areas that often have adequate resources to address these concerns, this is not the case in rural areas that struggle with more addicts and offenders than resources to manage this current crisis. Because of the complexity of the opioid crisis and many of the past lessons learned from the crack cocaine epidemic of the 1980s, we believe that society can more effectively address the new opioid epidemic by relying on both criminal justice as well as public health strategies.
\end{abstract}

Keywords: criminal justice approach, epidemic, opioid crisis, public health approach, strain theory

\section{Introduction}

Health experts and criminal justice officials report that within the past two decades, an opioid epidemic has spread across the United States causing an increase in negative health concerns as well as spikes in the crime rate (ManchiKanti et al., 2012; Dasgupta et al., 2014; Ford and Dulaney, 2013; Townes, 2016). Some drug experts attribute this increase to the prevalence of chronic pain that has manifested in drug addiction, while others see it as a problem that rests with the liberalization of laws created by state medical boards that proscribe opioids for treating chronic non-cancerous pain (ManchiKanti et al., 2012; Dasgupta et al., 2014). Moreover, in its 2010 report, the National Survey on Drug Use and Health revealed that an estimated 22.6 million Americans age 12 or older were either currently using illicit drugs or had done so in the past month. The survey also showed that an alarming number of Americans abuse pain relievers, as well as receive drugs from someone other than a health care provider. Health officials argue the opioid epidemic has reached the point of a national crisis since statistics show that in 2011, doctors wrote an estimated 136.7 million prescriptions for therapeutic opioids such as hydrocodone. They also wrote over 238 million prescriptions for other narcotic analgesics (ManchiKanti et al., 2012; Also see Hirschi et al., 2014). Similarly, Hudson (2016) reports that each day in the U.S., an estimated 80 people die due to overdosing on opioids. At the same time, criminal justice officials report an increase in numbers of opioid related deaths contending that they outnumber deaths from suicides and motor vehicle crashes, or deaths from the combined use of cocaine and heroin. They also find that when opioid users cannot get enough prescription drugs for pain management, many turn to crime to get the money to buy drugs on the street, typically in the form of stolen opioids such as oxycodone or Vicodin. Experts also report that there has been an increase in heroin use to self-medicate pain. Surprisingly, in some jurisdictions around the country, especially North Carolina, many law enforcement officers believe addicts would be better served by being taken to treatment centers rather than jail (see Townes, 2016).

Health officials argue that opioids are agents that produce their biological effects by binding to opioid receptors. Their primary clinical use is to treat and prevent pain. Pain is transmitted from neuron to neuron and travels to different parts 
of the spinal cord and brain. Neurotransmitters are the molecules that are released from nerve terminals and transmit pain signals. When opioids are administered to relieve pain, they inhibit the release of neurotransmitters. Katzung (2004), provides that some major opioid analgesics include: morphine, hydromorphone, oxymorphone, methadone, mependine, fentanyl, sufentanil, alfentanil, levorphonol, codeine, hydrocodone, oxycodone, propoxyphene, pentazoncine, nalbuphine, buprenorphine, and butorphanol. While any of these opioids can be dangerous and pose serious health consequences when abused, the purpose of this paper is to focus on opioid addiction, especially heroin and its abuse in rural North Carolina. As such, this paper will be divided into four parts. Part One presents opioid abuse in rural North Carolina. Part Two offers the strain theory to reveal how and why users abuse opioids. Part three discusses public health approaches to the opioid epidemic. Part four presents criminal justice approaches to the opioid epidemic. In the end, we argue that a blended approach from the criminal justice and public health systems can significantly reduce the opioid epidemic.

\section{Opioid Abuse in Rural North Carolina}

Recent drug reports show that there has been a $400 \%$ increase in opioid medication deaths in North Carolina that spanned from 1999 to 2012. Despite this staggering statistic, Townes (2016) reports that the numbers are now higher revealing that from 2010 to 2014, heroin-related deaths in North Carolina skyrocketed by 565\%. Research conducted by Dasgupta and colleagues (2014), find that within the past two decades, there has been a societal transition from prescription opioids to heroin which accounts for most overdose deaths. More specifically, they report that from 2007 to 2013, there were 4,787 opioid related deaths, 455 involved heroin, 4,332 involved prescriptions, and 44 involved a combination of both. In the end, their investigation revealed a gradual six-year shift towards heroin deaths. Nevertheless, some health professionals and law enforcement officials argue many deaths may be linked to the stigma attached to being a drug user and how it prevents addicts from seeking medical assistance. Moreover, Townes (2016) posits that criminalizing addicts for crimes they commit to buy drugs, do not prevent the behavior. In fact, in rural North Carolina, especially in Nash County, police officers express that arresting some drug offenders is not the sole answer, or the best response to these offenders. For example, the Nashville Police Chief introduced the HOPE initiative that offers treatment and counseling to heroin users who turn themselves in to police departments. Furthermore, policymakers have also gotten involved by drafting North Carolina's Good Samaritan legislation or Senate Bill 20 that deregulates the use of Naloxone and provides limited immunity to some drug addicted offenders who ask for medical assistance if they believe they or someone known to them may overdose on opioids.

Health experts report that the opioid epidemic is not only found in urban cities of North Carolina in places such as Charlotte, Raleigh, and Wilmington (the latter city has been cited as having the highest amount of opioid abuse in the nation), but rather, it is also pronounced in rural areas such as in Nash, Wilkes, and Wilson counties (Sisk, 2016). In fact, the same experts argue that no community in the state has shown itself to be immune from opioid addiction, abuse, and the devastation that comes along with it (Stephen, 2016; Hudson, 2016) including overdose deaths (most from prescription pain killers, but many from heroin use), increase in Hepatitis B and C cases, and an increase in crime arrests to procure monies to defray the cost of illegal drugs such as heroin, meth, and other opioids (AAFD News, 2014; Dasgupta, 2014). Further, Sisk (2016), reports that from 1999 to 2003, Nash County had only six overdose deaths and Wilson County had only four overdose deaths. However, the numbers vastly increased from 2010 to 2014, where the number of deaths from opioid overdose climbed to 27 and 22 for Nash and Wilson, respectively. Some reports reveal that rural law enforcement officers across the nation are confiscating heroin found on many suspects during arrest (Sisk, 2016).

In a recent survey that compiled the top 25 cities across the country with the highest rate of opioid abuse, four cities in North Carolina featured prominently in those statistics. For example, the survey revealed that Hickory, NC ranked fifth at 9.9 percent, Jacksonville, NC ranked 12th at 8.2 percent, and Fayetteville, NC ranked 18th at 7.9 percent, respectively. Wilmington, NC ranked number one. This finding is shocking to drug experts and others in public health since many believe opioid abuse in general, but heroin use and abuse in particular, is a big city problem thought to be commonly found in places such as New York City, Los Angeles, Chicago, and Miami (Sisk, 2016). Nevertheless, the survey also revealed that 22 of the top 25 cities were in the south. Consequently, many health experts now believe that opioids abusers are more likely to be from southern states. What is more interesting about the increase in opioid use is the type of people who are using these drugs. For example, a report by the Centers and Disease Control and Prevention (CDC), revealed that in recent years, the most extreme use of heroin has been found among groups that have not historically been known for using illicit drugs. They include women, those with private insurance, and with higher income (Sisk, 2016). Similarly, Torpy (2015) reported that there has been growth in the number of opioids related deaths among middle-aged white males in rural Georgia and other areas of the country who struggle with the changing economy and providing for their families in the future. Moreover, CDC data from 2012 revealed that the rate of opioid deaths in nonurban areas was 45 percent higher than those that occurred in urban areas around the nation (Sisk, 2016). 
Some drug experts contend that the devastation of opioid addiction has been more pronounced in rural North Carolina compared to urban settings because small towns are less prepared to address the influx of drugs and the negative health consequences that follow. More specifically, health experts warn that rural towns lack resources needed for prevention and treatment programs that are found in urban cities such as New York, Los Angeles, Chicago, and Miami where there is more money for treatment and prevention programs. As such, vitally needed treatment options are often limited and not accessible to local residents. This, in itself, worsens the problem in rural areas since drug addicts are likely to continue using and engaging in crime to support their habit. Moreover, Galea and colleagues (2003) argue that access, or the lack thereof to health care, poverty, and unemployment, painful conditions, risky behavior and other broader societal determinants also influence heroin use.

\section{Robert Agnew's General Strain Theory and the Use of Opioids}

Robert Agnew's General Strain Theory can be used to explain the effects of strain and why people use and become addicted to opioids. Agnew's theory provides explanatory power that addresses individual behavior. In fact, Agnew explains why people, regardless of social class, experience strain that could lead to crime. His view of criminal activity examines all segments of society, rather than targeting crimes solely committed by lower-class people (Agnew, 1992). Agnew argues that criminality is a manifestation of negative experiences and emotions caused by personal strain. These experiences often lead to feelings of anger, frustration, disappointment, depression, or fear that develop as a result of destructive relationships. Agnew presents four categories of negative emotions that include: the failure to achieve positively valued goals; disjunctions of expectations and achievements; removal of positively valued stimuli; and presentation of negative stimuli (Agnew, 1992). First, a failure to achieve positively valued goals occurs when one's structural means do not allow the acquisition of cultural goals. This occurs when people desire economic and material attainment, but lack legitimate resources to obtain them. According to the theory, this leads to strain and negative emotions. Second, the disjunction of expectations and achievement can be experienced by anyone regardless of economic status. For example, one can experience strain if he or she cannot get ahead or perceives others are doing better or achieving their goals (especially with respect to race, ethnicity, or economic background). Those who experience strain, may lash out, acquire things illegitimately, or seek alternatives to cope with the situation. Third, the removal of positively valued stimuli creates strain after something valued is removed, taken, or lost. Consequently, one may commit crimes to maintain his or her standard of living. Finally, the presentation of negative stimuli creates strain when one experiences victimization, punishment, abuse (e.g., drug dependency), failure, or any behavior believed an affront to one's dignity (Agnew, 1992).

Since every negative emotion that Agnew discussed in his theory is not needed to explain the increase in opioid use and addiction, this section primarily focuses on the failure to achieve positively valued goals, the disjuncture of expectations and achievements, and the presentation of negative stimuli (e.g., primarily opioid prescriptions or illegal drugs that manifest into addiction). These components of Agnew's theory are economic, psychological, and physical. They can be used to explain why people from all socioeconomic backgrounds use drugs in general, and opioids, in particular. Accordingly, the theory holds that if a person is either unable to attain economic prosperity, fails to meet financial expectations, or is dependent on prescription or illegal drugs, he or she will experience strain that could lead to crime. For example, if the job market does not accommodate the demands of the labor force, those who desire work will experience strain if they desire a certain standard of living. Moreover, those who desire to rise above their economic station, or people who become addicted to drugs will experience negative emotions or develop a need to acquire drugs. Consequently, these frustrations could steer some into drug use (more recently opioids) to cope with the realization that they are blocked from opportunities to support themselves as well as meet the needs of their families.

General strain theory argues that criminal behavior is a reaction to harmful emotions such as anger, depression, and anxiety, stemming from negative relationships with others including "noxious" circumstances, such as constant pain that could prevent some from obtaining desired goals (Agnew, 1992). It is the negative effect or primarily depression that can lead to avoidance or mediating criminal "internalizing behavior" including substance use (Slocum, 2010). Miller and Lynam's (2001) research revealed personality traits, such as "negative emotionality," caused some to experience negative emotions and "breakdown under stress" or strain. Similarly, Agnew (2006) addressed the perceptions of stressful events and how people's reaction to them could lead to a cycle of strain and criminal behavior. As stressful events that precipitate and result from criminal behavior, including substance use, accumulate, stressor amplification may occur. Moreover, Agnew and colleagues (2002) reported a relationship existed between the strain of being economically disadvantaged (see also Schroeder et al., 2011), and certain types of criminal behavior. This is particularly true for poor, minority women with children. Slocum (2010) added another critical factor, the experience of stress over a portion of the life cycle, or the duration of strain, which she referred to as stress proliferation, leading to chronic strain (Perlin et al., 1981) that could result in stable and continued use of substances. In effect, there may be "life trajectories" set in motion by stressors and maintained by strain including the initial and continued use of 
substances (Slocum, 2010).

In their investigation, Schroeder and colleagues (2011) examined poor health conditions including pain which may cause strain that prohibits people of all ages from achieving their goals. They found that pain not only prohibits the attainment of positive goals, but it also eliminates existing positive activities, such as going out in the community, performing work, participating in sports, attending educational institutions, and essential aspects of parenting which invariably leads to psychological distress and frustration (p.22). Despite this, Jang (2007) finds that while men disproportionately respond to strain with anger, females who experience high levels of strain report suffering from depression and anxiety. Along with these, men and women may also experience sadness, hopelessness, fear, and worry (Schroeder et al., 2011). Any single or a combination of these negative emotions could be a situational event, such as a financial crisis, that triggers criminal coping such as substance abuse (p.29).

Recent research reveals that strain resulting in substance abuse has not been ethnically or culturally exclusive. In fact, a study by Case and Deaton (2015), reveals that from 1999-2013, there has been a substantial increase in the morbidity of white non-Hispanic Americans, particularly between the ages of 45-54. Likewise, the Centers for Disease Control and Prevention (CDC) (2016), reports the same increase in overdoses among an even younger group with increased mortality found among those between the ages of 25-54. More specifically, it reveals that from 2000 to 2014, nearly a half million people died from drug overdose which amounts to 78 Americans dying each day owing to opioid overdose (CDC, 2016b). Additionally, health officials believe the opioids related to these deaths were mostly obtained by prescriptions since there has been a fourfold increase in the amount of prescriptions for opioids (especially Methadone, Oxycodone, and Hydrocodone) sold since 1999. The CDC also provides that the negative consequences of over-prescribing drugs go beyond overdose. For example, health experts reveal that in 2014, nearly 2 million Americans were reported to have abused or were addicted to prescription opioids, and almost 1,000 persons per day were treated in emergency care for prescription opioid misuse (CDC, 2016a). Both addiction and the need for emergency care are considered sources of strain. Furthermore, some scholars attribute this increase to the rise in strain indicated in "lowered self-reported health and mental health, increased reports of pain, and greater difficulties with daily living" (Case and Deaton, 2015). Moreover, Case and Deaton report that drug poisoning (accidental or unintentional) is one of the three leading factors associated with the rise in mortality among white non-Hispanics, along with suicide and liver disease. They report that both suicide and drug poisoning increases were greater among those with the least education. They also found that the mortality rate from drug poisoning underwent a fourfold increase. Moreover, they revealed the link between decreased self-assessed health and increased reports of pain associated with all body regions: neck pain, face pain, joint pain, and sciatica. Research by Case and Deaton showed that among those who experienced increased difficulty with activities of daily living, many also reported significant levels of psychological distress or strain. While citing the increased availability of opioids as paralleling the increased rate of mortality, Case and Deaton (2015) revealed that it is difficult to determine which came first, the rise in opioid abuse or a rise in pain, as long-term opioid use has been found to exacerbate pain for some.

In their study, Stogner and Gibson (2010) examined a health strain hypothesis involving the physical ailments that lead to strain and criminal behavior, such as substance use and the inability to access appropriate healthcare for treating the source of pain or illness, as well as the substance abuse or addiction (McCabe \& Wahler, 2016). They argued that this leads to increased strain and forces those needing healthcare to act criminally when barred from legal medical assistance. Opioids taken from the pharmacy and sold on the street is a public health issue itself (Dasgupta et al. 2013). However, it may be the only source of pain alleviation that some people have access to, which means that they could face more risks: potentially dangerously modified drugs, absence of medical monitoring, and association with drug traffickers. These often lead to increased strain.

\section{Public Health Approaches to the Opioid Epidemic}

The dramatic rise in opioid pain relievers (OPR) caused by prescription and illegal means has led to an unprecedented increase in opioid overdoses. Health officials as well as criminal justice experts have labeled this epidemic a national crisis. In fact, in 2013, the $C D C$ added the prevention of mortality from opioids to the list of public health challenges. Among the list, prescription drug abuse and overdose ranked second among the five top health threats for 2014 (CDC, 2014). Ironically, in 1995, the American Pain Society launched a campaign encouraging physicians to increase the use of opioids for non-cancer pain treatment (Campbell, 1996). Moreover, to respond to some physicians' reluctance to treat pain with opioids, opioid manufacturers published research citing low risk for addiction (Portenoy, 1996).

Although the highest numbers of opioid related deaths occur among people between the ages of 45-54, the greatest increase in opioid related mortality is found among persons between the ages of 55-64 (Kolodny et al., 2015). However, the nonmedical use of OPRs is more prevalent among people between the ages 15-24 (SAMHSA, 2009). Despite this, opioid overdose and deaths occur among adult medical OPR users more frequently than non-medical young users 
(Kolodny et al., 2015). Because of the age of users and that overdose is high among both medical and non-medical OPR users, public health strategies must employ a variety of formats. To that end, Kolodny and colleagues (2015) argue that opioid overdose prevention efforts should take the form of three categories: primary, secondary, and tertiary preventions. First, primary prevention must target overdose cases caused by the medical use of OPRs, as well as those linked to non-medical use. The most crucial point of prevention for medical related cases must target the prescribing physician. This requires that physicians are informed of the risks associated with OPRs and that they must follow rigid guidelines when prescribing opioids. Health care experts argue that federal and state agencies must also participate in these efforts. In fact, the Federal Drug Administration (FDA) released a revised Risk Evaluation and Mitigation Strategies (REMS) for prescribing extended-release and long-acting opioids in 2014. Though the FDA was asked to require all physicians who prescribe medication to undergo mandatory training, it relented, and instead ordered that manufacturers of opioid medications solely bear responsibility for making education programs available to prescribers for continuing education credits and to make educational information accessible to patients (FDA, 2014). The FDA also advised that this protocol receive periodic evaluation. Critics of the FDA effort report that some of the education received by OPR prescribers place the OPRs in a positive light and may encourage continued prescribing, rather than curbing it by providing accurate information about OPR risks (FDA, 2011).

Research reveals that several states support the DEA's effort to pass laws enforcing penalties on "pill mills." These efforts allow physicians to examine patients' pharmacy activity for controlled substances. In Washington State, the law mandates the use of evidence for tracking a patient pain level and functional status while being prescribed OPRs (Okie, 2010). Additionally, in March 2016, the CDC released the Guideline for Prescribing Opioids for Chronic Pain-United States, 2016. The difference between the old and new guidelines were threefold: First, the dosage recommendations for exercising caution are lower," because small doses are also risky; Second, prescribers are urged to use "safety precautions" with every patient and not only those considered high risk, and prescribers are encouraged to use state prescription drug monitoring programs. Third, "more specific recommendations [are made] on monitoring and discontinuing opioids when risks and harms outweigh benefits" (CDC, 2016b). Additionally, educational webinar series and physicians' use of non-pharmacologic methods of treating chronic pain were also recommended. For patients, the guidelines provide information about the risk of abuse and addiction, as well as information on the nature of OPRs. The state of New York has implemented additional guidelines to address opioid abuse. For example, New York released emergency room OPR guidelines in 2013 (New York City Department of Health and Mental Hygiene, 2013). More specifically, it introduced a two-prong primary prevention strategy for non-medical use of OPRs in an effort to reduce prescribing OPRs to institute prescription drug "take back" opportunities whereby patients can safely return unused OPRs to keep them off the streets, prevent them from being smuggled as contraband into jails and prisons, and from being used by friends and family (Kolodny et al., 2015).

Next, secondary prevention efforts are designed to screen conditions before they become dangerous issues, such as OPR abuse before it becomes OPR addiction (Kolodny et al., 2015). In the absence of effective screening tools and trained personnel working in primary care offices, prescription drug monitoring programs (PDMPs) have become a viable option. PDMPs are state operated electronic databases that monitor prescribed controlled substances (CDC, 2016a). They attempt to detect patients who are doctor shopping or patients who get prescriptions from several doctors by two mechanisms: physicians and pharmacists can consult the PDMP before prescribing or, they may practice in a state that sends out unsolicited reports identifying patients who regularly seek drugs (Kolodny et al., 2015). Another benefit of PDMPs is that they prevent drugs from being diverted to illegal sales (CDC, 2016a). Some states have made PDMPs mandatory, while others have recommended their use; prescribers can enter data into the system in real-time, thus maximizing its effectiveness; they can be utilized by public health entities to track the use of OPRs to inform intervention practices; and they can be made easily accessible and user-friendly for prescribers (CDC, 2016a).

Third, tertiary prevention measures entail treatment, including harm reduction practices. However, the persons needing this treatment the most, primarily lower-income persons who lack insurance have had the least access to it. Those who are most addictive are likely to experience greater difficulty maintaining or finding employment. Therefore, their treatment will be severely limited, unless they live in a state that provides Medicaid expansion (McCabe \& Wahler, 2016). Treatment for addiction should also cover co-occurring medical or mental health disorders. However, the health system is currently fragmented and makes holistic, "chronic disease management" costly and unavailable to those lacking healthcare insurance (McCabe \& Wahler, 2016, p. 228). According to SAMHSA (2013), the 2012 National Survey on Drug Use and Health revealed that nearly 2.1 million Americans were addicted to OPRs with another 467,000 addicted to heroin. Despite this grim figure, some argue the number of persons experiencing opioid addiction might exceed 5 million (Kolodny et al., 2015). Treatment may consist of detox, long-term inpatient and outpatient, psycho-social education, self-help group attendance, and pharmacotherapies such as methadone maintenance and buprenorphine maintenance (569). Kolodny and colleagues also recommend access to Naloxone, the opioid overdose 
antidote preventing opioid overdose deaths, as a tertiary prevention method.

Another tertiary measure to prevent opioid addiction is stricter regulations in drug marketing. For example, under the Food, Drug, and Cosmetics Act, the FDA is responsible for approving drug marketing material when it is disseminated. However, it is difficult to measure accountability. In the past few years, pharmaceutical companies have faced criticisms for marketing tactics that promoted the use of opioids. Moreover, Chicago and two counties in California are suing five drug companies for "aggressive marketing" that "has fueled an epidemic of addiction and cost taxpayers millions of dollars in insurance claims and other health care costs" (Schwartz, 2014). Recently, Pfizer agreed to modify its marketing of opioids "to disclose in its promotional material that narcotic painkillers carry serious risk of addiction even when used properly. Additionally, it promised not to promote opioids for unapproved, "off-label" uses such as long-term back pain" (Pfizer agrees to truth in opioid marketing, 2016). Critiques argue that Pfizer was likely reacting to the FDA's newest guidelines on labeling, for immediate-release (IR) opioid pain medications, which included the requirement of a "new boxed warning about the serious risks of misuse, abuse, addiction, overdose and death," among other safety labeling changes for all opioid medications.

\section{Criminal Justice Approaches to the Opi oid Epi demic}

Illegal drug use and their distribution are criminal justice issues since they have serious consequences often diminishing the quality of life of law-abiding community residents, as well as contributing to large numbers of arrestees entering into the justice system. Many people believe that there is a nexus between the presence of drug users, addicts, and more crime. While this appears commonsensical, not everyone fully agrees. Stated differently, the relationship between drug use, addiction, and crime is well documented in the criminological literature, but some scholars and drug experts warn that a linear relationship may not exist (see Inciardi, 1981; McBride and McCoy, 2003; Bean, 2014; Schram and Tibbetts, 2014). Notwithstanding, communities that have a drug presence are typically places where one finds a high crime rate that includes: robberies, violent shootings, burglaries, deaths, and accidental overdoses. They are also places where sex work (from both male and female prostitutes) occurs whereby addicts often engage in unsafe and unprotected sexual behaviors to earn money needed to buy drugs. Despite this, Peak and Everett (2017) argue that an increasing problem now confronting society and the criminal justice system is the abuse of prescription painkillers. They provide that an estimated 100 million Americans or nearly a third of the U.S. population suffers from chronic pain and even more alarming is the fact that in an effort to provide relief, health care professionals write nearly 219 million opioid prescriptions annually (also see Calabresi, 2015).

Because of lessons learned from the past war on drugs, experts and criminal justice officials are trying different approaches compared to those that were used in minority communities (e.g., disproportionately black and Latinos) during the mid-1980s and the early 1990s. For example, research conducted by Chappell and Maggard (2007) revealed that in their efforts to fight the war on drugs, states throughout the nation passed severe laws that handed down harsh sentences to offenders found in possession of crack or "rock" cocaine. They argued these laws o verwhelmingly targeted the poor by imposing stringent punishment for possessing crack cocaine, while at the same time, giving substantially less punishment to middle and upper class white offenders who were in possession of large quantities of powdered cocaine. Moreover, many impoverished communities experienced living under a "police state" or police occupation followed by unprecedented numbers of arrests where tough mandatory sentences were routinely imposed. In fact, to address what many politicians, scholars, community residents, and organizers now believe were discriminatory drug laws, in 2010, President Barack Obama signed The Fair Sentencing Act to help decongest many of the nation's overcrowded prisons, especially those housing offenders who were unfairly sentenced by disparate laws that targeted minority communities in general, and young black and Latino males, in particular. More specifically, the Act was designed to reduce the disparity in the amounts of powder cocaine and crack cocaine designed to trigger penalties in the federal system, namely mandatory minimum sentences that devastated and destabilized poor minority communities across the country (Messner \& Rosenfeld, 2013). Notwithstanding, penologists argue the U.S. imprisons over 2.5 million offenders, many of whom are confined because of drug violations and are viewed in many cases as the casualties of the drug war of the 80s and 90s (Hanser, 2017).

Since past efforts used to fight the war on drugs resulted in racial profiling, unequal treatment, prison overcrowding, and the need to reform the justice system (including the implementation of community-based correctional initiatives to reduce prison overcrowding), criminal justice experts believe these efforts have informed the changing views regarding how the war on drugs should now be waged (see Peak and Everett, 2017). For example, critics of past practices and policies argue that an effective criminal justice response to the national drug crisis in general, but the use of opioids in particular, must go beyond simply arresting and charging addicts for drug offenses. To the point, Schram and Tibbetts (2014) argue that contemporary approaches to reduce opioid use are fourfold: interdiction strategies; eradication strategies; drug courts; and harm reduction. First, interdiction occurs when law enforcement agencies (e.g., local, state, and federal) engage in efforts to stop the flow of drug trafficking. Law enforcement experts contend that disrupting the 
flow of illegal drugs (especially the distribution of opioids), is essential to combating the drug problem. They argue that this strategy is not simple since research reveals the steps involved in drug interdiction include: providing intelligence sharing, detection, distinguishing drug smuggling traffic from legitimate traffic, trafficking and or intercepting contacts, shifting primary responsibility between forces or actors, stopping activities (especially the flow of opioids), detention, arrest, seizure of suspects and evidence to gain a criminal conviction, and prosecution during criminal proceedings (Office of National Drug Control Policy, 2010). To have a chance of succeeding in interdiction efforts, in 1988, Congress passed the Anti-Drug Act which focused on reducing drug trafficking and production in the U.S. by facilitating cooperation between local, state, and federal law enforcement agencies in sharing information, intelligence, and coordinating strategies to prevent drug trafficking.

The Anti-Drug Act created High Intensity Drug Trafficking Areas (HIDTA) program. More specifically, there are currently 28 programs in the U.S. that are located in counties throughout 46 states, the Virgin Islands, and the District of Columbia (Office of National Drug Control Policy, 2010; also see Schram and Tibbetts, 2014). HIDTA are believed to be effective because they employ multiagency investigations, interdiction, and prosecutions. They are also involved in prevention and treatment efforts (Office of National Drug Control Policy, n.d.). Research reveals that the Ohio area HIDTA encompasses eleven counties that include links to major drug source regions such as Chicago, Detroit, New York City, the Southwest Border, and Canada. It also found that many interstate highways are used to traffic illegal drugs throughout the region. Moreover, Ohio's HIDTA reported that over the past 25 years, commercial truck trafficking has increased by $90 \%$ and is expected to increase by $60 \%$ by 2020 . Furthermore, it revealed that because of the addictive nature, an increase in cocaine is likely to threaten the Ohio HIDTA area (Ohio High Intensity Drug Trafficking Area, 2009).

Second, eradication is another strategy used to fight and reduce illegal opioids from entering the U.S. Gaines and Kappeler (2008) argue that while many drugs are manufactured in the US, heroin and other opioids are imported from Mexico, Afghanistan, Iran, Myanmar, Laos, and Thailand. Eradication focuses on destroying drugs, especially opium poppy, the coca bash, and cannabis plants (Farrell, 1999). Farrell provides that while there are four types of eradication techniques, namely: mechanical destruction, burning, chemical, and biological (e.g. genetic), the mechanical and chemical strategies are most often used. Criminal justice experts in general, and drug enforcement officials in particular, report that over the years, eradication efforts have been successful. In fact, the National Drug Intelligence Center (2008), reported that eradication efforts in Columbia to prevent the production of coca plants, resulted in an 8 percent decrease worldwide in 2007. Similarly, cocaine production in Peru has also declined owing to forced and voluntary eradication efforts. Within the U.S. borders, eradication efforts have also been successful. For example, the DEA reports that cannabis eradication and suppression programs are increasing in the western as well as eastern states. More specifically, these programs are appearing in cultivation states such as Hawaii, Tennessee, Kentucky, Washington, and West Virginia. The $D E A$ also reports that to elude detection, drug traffickers have switched to indoor cultivation. Drug experts argue that indoor cultivation is more challenging to law enforcement officials since it is unseen and can be cultivated perennially. The DEA also reports that with states decriminalizing the use of marijuana for medical use and in some areas for recreational use, it is difficult to know the effects of eradication efforts, especially in light of states that are decriminalizing its use, while the federal government remains steadfast that the behavior violates federal law (National Drug Intelligence Center, 2009).

Third, experts argue that because of the war on drugs, offenders clog the criminal justice system at every level and are expensive to process. To offset the influx, drug courts have been created. While initially introduced in the latter 1980s, as drug use and addiction increased, especially among opioid abusers, so too, has the need to create more drug courts for this special population of offenders (Lurigo, 2008). Drug courts are a popular strategy used to combat substance abuse issues, drug addiction, and its corresponding crime. They offer drug offenders an opportunity to participate in treatment and counseling programs or receive incarceration. While drug courts across the U.S. have different standards, they share some commonalities such as the duration of drug treatment programs (typically 12 to 24 months) and the components that participants experience. According to Gaines and Kappeler (2008), drug court treatment programs contain three phases. First, participants experience regular supervision, frequent meetings and drug testing. Second, they receive drug treatment and programs design to improve their life chances. These programs often include job training, life skills, and GED completion. In the third phase, participants are followed after completion of the program and are provided more job training skills. Gaines and Kappeler provide that as participants move through the three phases, they receive less supervision from program officials.

Drug courts are believed to be cost-effective since they expedite case processing, provide outpatient treatment and support services (Harrell, 2003). They also save limited correctional dollars since they are an alternative to prison for many nonviolent offenders (Gottfredson, Najaka, \& Kearley, 2003). They provide job placement and housing, mandatory drug testing and intensive court or probation supervision (Lurigio, 2008; also see Fox and Huddleston, 2003). 
Unlike other criminal courts, these courts rely on the combined efforts of justice and treatment professionals to assist drug addicts with ending the downward spiral of addiction and crime (Fox and Huddleston, 2003). Moreover, Huddleston and colleagues (2008), argue that offenders identified as substance abusers are placed under judicial monitoring and community supervision and provided long-term treatment services. In these programs, offenders participate in drug treatment and testing, probation supervision, and report to scheduled status hearing before a judge (see Fox and Huddleston, 2003). Justice experts argue that there are advantages to participating in drug court ranging from having one's charges missed or reduced, getting one's substance abuse problem addressed, acquiring employment, and in some cases, retaining custody over one's children (Cooper, 2007). Sechrest (2003) reported that drug courts are successful at reducing drug use among participants. In fact, one study found that drug court graduates were rearrested at a rate of $16.4 \%$ per year compared with a rate of $43.5 \%$ for nonparticipants for the same period (The White House, 2007). Despite this, Wolfer (2006) contends there are disadvantages attached to these programs that include the pretest bias of awareness of scheduled urine tests allow participants to pass this phase of the program, and that the programs are viewed as unfair since they address individual needs and lack uniformity.

Fourth, some drug experts advocate a harms reduction approach to prevent illegal opioid use calling for policies that incorporate a public health approach to reduce the harm associated with illegal drug use (McBride et al., 2009). These experts view drug use as a public health, rather than a criminal justice problem (Haden, 2004; MacMaster, 2004). The harms reduction approach is viewed by some as unconventional, unethical, and in some cases, its legality has been questioned (Burris et al., 1996). One example of a popular harms reduction program is needle exchange. It includes: providing sterile needles (e.g., needle exchange), outreach efforts, substituting opioids for methadone, and providing facilities for supervised injections. Experts argue that such programs allow drug users to receive treatment for medical and psychological help (Barkan, 2006). Needle exchanges are used since many people, as well as health officials are concerned about the pervasiveness and dangers associated with drug addicts sharing contaminated syringes or "dirty" needles. Therefore, these programs provide clean and unused syringes to intravenous drug users. Health officials and justice experts argue the approach is effective in reducing the spread of HIV, hepatitis B and C, and other viruses that could pose a threat to the community if needle sharing occurs. These programs also offer counseling and referrals to drug treatment programs (see Delgado, 2004). In fact, Duff (2010) reports that exchange programs make drug use safer and promote healthier behavior among addicts. Moreover, exchange programs provide educational materials that highlight the dangers linked to needle sharing and the spread of STD's. They also supply bleach bottles, cotton swabs, skin ointment, and condoms.

Regardless of the benefits of having needle exchange programs, some researchers have examined the legality of such programs and have expressed concerns over possible violations over existing drug paraphernalia laws. More specifically, there have been mounting concerns regarding the manufacture, possession, and distribution of drug paraphernalia. Researchers argue that these are illegal in 46 states and Washington, D.C. For example, Burris and colleagues (1996) conducted research that examined 49 needle exchange programs to determine whether they operated legally. Their study found that some of the programs $(n=9)$ violated local laws and their participants risked being criminally prosecuted for violating drug paraphernalia laws. Moreover, several other programs $(n=27)$ were either directly or indirectly authorized by state amendment or judicial interpretation of the law to be exempted from prosecution (Burris et al., 1996). They also found that the remaining programs $(n=13)$ had not been challenged and reviewed by the courts, but claimed their legality on the basis of being found under state public health and drug laws.

\section{Conclusion}

Because opioid addiction has reached the point of crisis in the U.S., effective responses will require that those addressing the issue rely on both criminal justice and public health strategies to reduce and treat the problem. As stated earlier, some sobering lessons learned from the crack epidemic of the 1980s and 1990s reveal that by treating the drug problem solely as a criminal justice issue instead of a health problem, it resulted in punitive measures with negative consequences, such as mandatory sentences, prison overcrowding, destabilization of minority communities, and a continued legacy of mistrust of police and the justice system. By viewing the current opioid epidemic as both a criminal justice and public health issue, it requires more than punishing drug users and offenders. It also requires recognizing the impact of opioid addiction and its byproducts that include a lack of productivity, absenteeism, lost wages, broken families, shattered lives, crime, spread of HIV/ AIDS, excessive emergency room care, overdoses, untimely deaths, and others. Surely, these negative consequences go beyond criminal justice and therefore, cannot be adequately addressed by the agencies in the justice system (e.g., police, courts, corrections). Notwithstanding, Schneider (2000) contends that when the public's health is threatened, society in general, and the government in particular, must respond with viable solutions. To that end, President Obama recently signed into law the Comprehensive Addiction and Recovery Act of 2016 to address the opioid epidemic. 
The Act has a sixfold purpose that enlists criminal justice and public health strategies. First, it provides prevention and education efforts to teenagers, parents, aging populations, and caregivers to prevent abuse of amphetamines, opioids, and heroin. Second, it allocates resources to identify and treat incarcerated offenders who suffer addiction. Third, it increases the number of disposal sites for unwanted prescription medication. Fourth, it initiates an evidence based opioid and heroin treatment and intervention program to expand best practices throughout the nation. Fifth, it launches a medication assisted treatment and intervention demonstration program. Finally, it provides for strengthening prescription drug monitoring programs to help states monitor and track prescription drug diversion used to help at-risk individuals access service. While the Act alone is not meant to serve as a panacea, it defines opioid addiction as a health issue that requires a medical and healthcare approach that also extends to incarcerated offenders. Since millions of Americans suffer from opioid addiction, this federal effort along with state sponsored programs are essential steps in addressing this national crisis, especially since it allocates monies to rural states such as North Carolina which lacks needed resources to adequately combat addiction and provide treatment programs. Similarly to the Comprehensive Addiction and Recovery Act, we support the use of existing prevention strategies from both the criminal justice as well as the public health systems. We believe that a failure to do so would lead to failed criminal justice as well as public health policy that could prove counterproductive in addressing opioid addiction.

\section{References}

Agnew, R. (1992). Foundation for a general strain theory of crime and delinquency. Criminology, 30(1), 47-87. https://doi.org/10.1111/j.1745-9125.1992.tb01093.x

Agnew, R. (2006). Pressured into crime: An overview of general strain theory. Los Angeles, CA: Roxbury Publishing.

Agnew, R., Brezina, T., Wright, J. P., \& Cullen, F. T. (2002). Strain, personality traits, and delinquency: Extending general strain theory. Criminology, 40, 43-72. https://doi.org/10.1111/j.1745-9125.2002.tb00949.x

Barkan, S. E. (2006). Criminology: A sociological understanding $\left(3^{\text {rd }}\right.$ ed.). Upper Saddle Rivers, NJ: Pearson/Prentice-Hall.

Bean, P. (2014). Drugs and Crime (4 ${ }^{\text {th }}$ ed.). New York, NY: Routledge Press.

Burris, S., Finucane, D., Gallagher, H., \& Grace, J. (1996). The legal strategies used in operating syringe exchange programs in the United States. American Journal of Public Health, 86, 1161-1166. https://doi.org/10.2105/AJPH.86.8_Pt_1.1161

Calabresi, M. (2015). The price of relief. Times, June 15, 2533.

Campbell, J. N. (1996). APS 1995 presidential address. Pain Forum, 5, 85-88. https://doi.org/10.1016/S1082-3174(96)80076-6

Case, A., \& Deaton, A. (2015). Rising morbidity and mortality in midlife among white non-Hispanic Americans in the $21^{\mathrm{s}}$ century. Proceedings of the National Academy of Sciences, 112(49), 15078-15083. https://doi.org/10.1073/pnas.1518393112

Centers for Disease Control \& Prevention. (2014). CDC's Top Ten: 5 Health Achievements in 2013 and 5 Health Threats in 2014. Atlanta, GA: CDC.

http://blogs.cdc.gov/cdcworksforyou24-7/2013/12/cdc's-top-ten-5-health-achievements-in-2013-and-5-health-threa ts-in-2014/

Centers for Disease Control and Prevention. (2016a). Injury Prevention \& Control: Opioid Overdose: Prescription Opioid Overdose Data. Found at http://www.cdc.gov/drugoverdose/data/overdose.html

Centers for Disease Control and Prevention. (2016b). Injury Prevention \& Control: Opioid Overdose: Understanding the Epidemic. Found at http://www.cdc.gov/drugoverdose/epidemic/index.html

Chappell, A. T., \& Maggard, S. R. (2007). Applying Black's theory of law to crack and cocaine sentencing. International Journal of Offender Therapy and Comparative Criminology, 51(3), 264-278. https://doi.org/10.1177/0306624X06293601

Cooper, C. S. (2007). Drug courts: Just the beginning: Getting other areas of public policy in sync. Substance Use \& Misuse, 42, 243-256. https://doi.org/10.1080/10826080601141982

Dasgupta, N., Freifeld, C., Brownstein, J., Menone, C., Surratt, H., Poppish, L., ... Dart, R. (2013). Crowdsourcing black market prices for prescription opioids. Journal of Medical Internet Research, 15(8). https://doi.org/10.2196/jmir.2810

Dasguta, N., Creppage, K., Austin, A., Ringwalt, C., Sanford, C., \& Proescholdbell, S. K. (2014). Observed transition from opioid deaths toward heroin. Drug and Alcohol Dependence, 145, 238-241. 
https://doi.org/10.1016/j.drugalcdep.2014.10.005

Delgado, C. (2004). Evaluation of needle exchange programs. Public Health Nursing, 21, 171. https://doi.org/10.1111/j.0737-1209.2004.021211.x

Duff, C. (2010). Enabling places and enabling resources: New directions for harm reduction research and practice. Drug and Alcohol Review, 29, 337. https://doi.org/10.1111/j.1465-3362.2010.00187.x

Farrell, G. (1998). A global empirical review of drug crop eradication and United Nations' crop substitution and alternative development strategies. Journal of Drug Issues, 28, 395-436. https://doi.org/10.1177/002204269802800207

Ford, M., \& Dulaney, A. R. (2013). Prescription drug overdose and misuse: Data from Carolinas Poison Center, N.C. Med $J ., 74,244$.

Fox, C. L., \& Huddleston, C. W. (2003). Drug courts in the U.S. Issues of Democracy, 8, 13-19.

Gaines, L. K., \& Kappeler, V. (2008). Policing in American ( $6^{\text {th }}$ ed.). Cincinnati, OH: Anderson Publishing.

Galea, S., Ahern, J., \& Ulahov, D. (2003). Contextual determinants of drug use risk behavior: A theoretical framework. J. Urban Health, 80, iii50-iii58. https://doi.org/10.1093/jurban/jtg082

Gottfredson, D., Najaka, S., \& Kearley, B. (2003). Effectiveness of drug treatment courts: Evidence from a randomized trial. Criminology \& Public Policy, 2, 171-196. https://doi.org/10.1111/j.1745-9133.2003.tb00117.x

Haden, M. (2004). Regulation of illegal drugs: An exploration of public health tools. International Journal of Drug Policy, 15, 225-230. https://doi.org/10.1016/j.drugpo.2004.03.006

Hanser, R. D. (2017). Introduction to corrections ( $2^{\text {nd }}$ ed.). Thousand Oaks, CA: Sage.

Harrell, A. (2003). Judging drug courts. Balancing the evidence. Criminology \& Public Policy, 2, 207-212. https://doi.org/10.1111/j.1745-9133.2003.tb00119.x

Hirschi, A., Proescholdbell, S. K., Bronson, W., \& Dasgupta, N. (2014). Prescription histories and dose strengths associated with overdose deaths. Pain Med., 15, 1187-1195. https://doi.org/10.1111/pme.12391

Huddleston, C. W., Marlow, D. B., \& Casebolt, R. (2008). A national report on drug courts and other problem-solving court programs in the United States. Washington, D.C.: National Drug Court Institute, 2.

Hudson, R. (2016). Opioid abuse: A national epidemic. The Ansor Record. May, 20.

Inciradi, J. (1981). Heroin addiction and street crime. In International narcotics trafficking: Hearings before the Permanent Subcommittee on Investigations. Washington, D.C.: U.S. Government Printing Office, p.59.

Jang, S. (2007). Gender difference in strain, negative emotions, and coping behaviors: A general strain theory approach. Justice Quarterly, 24, 523-553. https://doi.org/10.1080/07418820701485486

Katzung, B. G. (2004). Basic \& Clinical Pharmacology ( $9^{\text {th }}$ ed.). New York: Lang Medical Books/McGraw-Hill.

Kolodny, A., Courtwright, D., Hwang, C., Kreiner, P., Eadie, J., Clark, T., \& Alexander, G. (2015). The prescription opioid and heroin crisis: A public health approach to an epidemic of addiction. The Annual Review of Public Health, 36, 559-574. https://doi.org/10.1146/annurev-publhealth-031914-122957

Luirigio, A. J. (2008). The first 20 years of drug treatment courts: A brief description of their history and impact. Federal Probation, 72, 13.

MacMaster, S. A. (2004). Harm reduction: A new perspective on substance abuse service. Social Work, 49, 356-363. https://doi.org/10.1093/sw/49.3.353

ManchiKanti, L., Helms, S., Fellow, B., Janata, J. W., Pampati, V., Grider, J. S., \& Boswell, M. V. (2012). Opioid epidemic in the United States. Pain Physician, 15(3), 9-38.

Mars, S. G., Bourgois, P., Karandinos, G., Montero, F., Ciccarone, D. (2014). Every 'never' I ever said came true: Transitions from opioids pills to heroin injecting. Int. J. Drug Policy, 25, 257-266. https://doi.org/10.1016/j.drugpo.2013.10.004

McBride, D. C., \& McCoy, C. B. (2003). The drugs-crime relationship: An analytical framework. In L.K. Gaines \& P.B. Kraska (eds.), Drugs, crime, and justice ( $2^{\text {nd }}$ ed., 87-108). Prospect Heights, IL: Waveland Press, p. 100.

McCabe, H., \& Wahler, E. (2016). The affordable care act, substance use disorders, and low-income clients: Implications for social work. Social Work, 61, 227-233. https://doi.org/10.1093/sw/sww030

Messner, S. F., \& Rosenfeld, R. (2013). Crime and the American Dream ( $5^{\text {th }}$ ed.). Belmont, CA: Wadsworth. 
Miller, J. D., \& Lynam, D. (2001). Structural models of personality and their relation to antisocial behavior: A meta-analytic review. Criminology, 39, 765-795. https://doi.org/10.1111/j.1745-9125.2001.tb00940.x

National Drug Intelligence Center. (2008). Cocaine. In National drug threat assessment, 2009 (pp. 1-8). Washington, DC: Author. Retrieved from http://www.justice.gov/archieve/ndic/pubs31/31379/3137p.pdf

National Drug Intelligence Center. (2009). Domestic cannabis cultivation assessment. Washington, DC: U.S. Department of Justice. Retrieved from http://www.justice.gov/archieve/ndic/pubs37/37035/37035p.pdf

National Survey on Drug Use and Health. (2010). Substance Abuse and Mental Health Service Administration. Department of Health \& Human Services, Washington, DC.

New York City Department of Health and Mental Hygiene. (2013). New York City Emergency Department Discharge Opioid Prescribing Guidelines. Long Island City, NY: NYC Health. http://www.nyc.gov/html/doh/downloads/pdf/basas/opioid-prescribing-guidelines.pdf

Office of National Drug Control Policy. (2010). National interdiction command and control plan. Washington, DC: Author. Retrieved from http://www.whitehousedrugpolicy.gov/pdf/usic 2011-nicc.pdf

Office of National Drug Control Policy. (n.d.). High Intensity Drug Trafficking Areas (HIDTA) program. Washington, DC: Author. Retrieved from http://www. whitehousedrugpolicy.gov/ondcp/high-intensity-drug-trafficking-areas-program

Ohio High Intensity Drug Trafficking Area. (2009). Drug market analysis 2009. Washington, DC: National Drug Intelligence Center, U.S. Department of Justice.

Okie, S. (2010). A flood of opioids, a rising tide of deaths. The New England Journal of Medicine, 363(21), 1981-1985. https://doi.org/10.1056/NEJMp1011512

Oxford Dictionaries. (2016). http://www.oxforddictionaries.com/us/definition/american_english/strain

Peak, K. J., \& Everett, P. M. (2017). Introduction to criminal justice: Practice and process ( $2^{\text {nd }}$ ed). Thousand Oaks, CA: Sage.

Perlin, L., Menaghan, E., Lieberman, M., \& Mullan, J. (1981). The stress process. Journal of Health and Social Behavior, 22, 337-356. https://doi.org/10.2307/2136676

Pfizer agrees to truth in opioid marketing. (2016, Jul 05). [Video/DVD] Washington, D.C.: WP Company LLC d/b/a The Washington Post. Retrieved from http://search.proquest.com.jproxy.lib.ecu.edu/docview/1801773321 ?accountid=10639

Portenoy, R. K. (1996). Opioid therapy for chronic nonmalignant pain: clinicians' perspective. J. Law Med. Ethics, 24, 296-309. https://doi.org/10.1111/j.1748-720X.1996.tb01871.x

Schneider, M. J. (2000). Introduction to Public Health. Gaithersburg, MD: As Aspen Publication.

Schroeder, R., Hill, T., Haynes, S., \& Bradley, C. (2011). Physical health and crime among low-income urban women: An application of general strain theory. Journal of Criminal Justice, 39, 21-29. https://doi.org/10.1016/j.jcrimjus.2010.09.009

Schwartz, J. (2014). Drug makers are sued over opioid marketing: Local governments say that companies' tactics feed abuse and addiction. International New York Times, 17. (August 26).

Sechrest, D. (2003). Drug courts: What is their future? In L. Gaines and P. Kraska (eds). Drugs, Crime \& Justice, pp. 318-331. Prospect Heights, IL: Waveland.

Sisk, T. (2016). Heroin Lives Here. North Carolina Health News, Trends, and Policy.

Slocum, L. A. (2010). General strain theory and the development of stressors and substance use over time: An Empirical examination. Journal of Criminal Justice, 38, 1100-1112. https://doi.org/10.1016/j.jcrimjus.2010.08.002

Stephen, P. (2016). Study-Wilmington No 1 in Opioid Abuse. Sun Journal. New Bern, North Carolina.

Substance Abuse and Mental Health Services Administration (SAMHSA). (2013). Results from the 2012 National Survey on Drug Use and Health: Summary of national findings. NSDUH Ser H-46, DHHS Publication No. SMA 13-4795.

Substance Abuse and Mental Health Services Administration (SAMHSA). (2009). Trends in Nonmedical Use of Prescription Pain Relievers: 2002 to 2007. NSDUH Rep. Rockville, MD: SAMHSA

The White House, (2007). National Drug Control Strategy. Washington, D.C.: U.S. Government Printing Office.

Torphy, B. (2015). A silent epidemic is killing middle-age white folks in Georgia. The Atlantic Journal Constitution. November 11, Wednesday. 
Townes, C. (2016). North Carolina Police Chief Implores Offices to Stop Arresting Addicts. Think Progress.

United States Food and Drug Administration. (2011). Comment from Physicians for Responsible Opioid Prescribing on the Food and Drug Administration (FDA) Notice: Draft blueprint for prescriber education; availability: long-acting/extended-release opioid class-wide risk evaluation and mitigation strategy. Phys. Responsib. Opiod Prescr. (PROP), FDA-2011-D-0771-0069, Regulations.gov, Washington, DC. http://www.regulations.gov/\#!documentDetail;D=FDA-2011-D-0771-0069

United States Food and Drug Administration. (2014). News Release: FDA introduces new safety measures for extended-release and long-acting opioid medications. Found at http://www.fda.gov/NewsEvents/Newsroom/PressAnnouncements/ucm310870.htm

United States Food and Drug Administration. (2016). FDA News Release: FDA announces enhanced warnings for immediate-release opioid pain medications related to risks of misuse, abuse, addiction, overdose and death. Found at http://www.fda.gov/NewsEvents/Newsroom/PressAnnouncements/ucm491739.htm

Wolfer, L. (2006). Graduates speak: A qualitative exploration of drug court graduates' views of the strengths and weaknesses of the program. Contemporary Drug Problems, 33, 303-320. https://doi.org/10.1177/009145090603300206

\section{Statutes}

Senate Bill 20: General Assembly of North Carolina Session 2013

S.524: Comprehensive Addiction and Recovery Act of 2016

\section{Copyrights}

Copyright for this article is retained by the author(s), with first publication rights granted to the journal.

This is an open-access article distributed under the terms and conditions of the Creative Commons Attribution license which permits unrestricted use, distribution, and reproduction in any medium, provided the original work is properly cited. 